\title{
Prognostic Factors for Patients with Anal Cancer Treated with Conformal Radiotherapy - A Systematic Review
}

\author{
Stelios Theophanous ( $\nabla$ umsth@leeds.ac.uk) \\ University of Leeds \\ Robert Samuel \\ University of Leeds \\ John Lilley \\ Leeds Cancer Centre, St James's University Hospitals \\ Ann Henry \\ University of Leeds \\ David Sebag-Montefiore \\ University of Leeds \\ Alexandra Gilbert \\ University of Leeds \\ Ane L Appelt \\ University of Leeds
}

\section{Research Article}

Keywords: Systematic review, anal cancer, squamous cell carcinoma, conformal radiotherapy, IMRT, VMAT, cancer outcomes, survival outcomes, prognostic factors

Posted Date: February 14th, 2022

DOI: https://doi.org/10.21203/rs.3.rs-1324086/v1

License: (c) (i) This work is licensed under a Creative Commons Attribution 4.0 International License. Read Full License 


\section{Abstract}

Aims

Anal cancer is primarily treated using concurrent chemoradiotherapy (CRT), with conformal techniques such as intensity modulated radiotherapy (IMRT) and volumetric arc therapy (VMAT) now being the standard techniques utilised across the world. Despite this, there is still very limited consensus on prognostic factors for outcome following conformal CRT. This systematic review aims to evaluate the existing literature to identify prognostic factors for a variety of oncological outcomes in anal cancer, focusing on patients treated with curative intent using contemporary conformal radiotherapy techniques.

Materials and methods

A literature search was conducted using Medline and Embase to identify studies reporting on prognostic factors for survival and cancer-related outcomes after conformal CRT for anal cancer. The prognostic factors which were identified as significant in univariable and multivariable analysis, along with their respective factor effects (where available) were extracted. Only factors reported as prognostic in more than one study were included in the final results.

Results

The results from 19 studies were analysed. In both univariable and multivariable analysis, $\mathrm{N}$ stage, $\mathrm{T}$ stage, and sex were found to be the most prevalent and reliable clinical prognostic factors for the majority of outcomes explored. Only a few biomarkers have been identified as prognostic by more than one study - pre-treatment biopsy HPV load, as well as the presence of leukocytosis, neutrophilia and anaemia at baseline measurement. The results also highlight the lack of studies with large cohorts exploring the prognostic significance of imaging factors.

Conclusion

Establishing a set of prognostic and potentially predictive factors for anal cancer outcomes can guide the risk stratification of patients, aiding the design of future clinical trials. Such trials will in turn provide us with greater insight into how to effectively treat this disease using a more personalised approach.

\section{Background}

First reported in 1974 by Nigro et al. [1] and established by two phase III trials [2, 3], concurrent chemoradiotherapy (CRT) is the current standard of care for localised anal squamous cell carcinoma (ASCC). The introduction of three-dimensional conformal radiotherapy (3D-CRT), intensity modulated radiotherapy (IMRT) and latterly volumetric arc therapy (VMAT) [4] has allowed for substantial reduction in dose to pelvic organs at risk (OAR) and associated toxicity, with far fewer unplanned treatment breaks as a result. The current UK standard for anal cancer comprises of IMRT/VMAT and concurrent chemotherapy with 5-fluorouracil (5-FU) or capecitabine and mitomycin C (MMC), with surgery reserved as salvage treatment [5].

Anal cancer is a rare cancer, and only a handful of late phase clinical trials have been conducted over the last four decades [2, 3, 6-9]. Other than the single arm phase II RTOG 0529 [10] trial, these trials were conducted prior to widespread adoption of conformal radiotherapy techniques, such as 3D-CRT or IMRT/VMAT. Similarly, much of the published literature on prognostic factors in anal cancer consists of retrospective series, often small cohorts $[11,12]$ or cohorts of patients treated with older techniques $[13,14]$. No systematic review of studies identifying prognostic factors after treatment with conformal radiotherapy has previously been conducted.

Despite advances in radiotherapy planning and delivery, locoregional control remains challenging, and patients usually fail locoregionally before getting metastatic disease. A UK multi-centre retrospective review by Shakir et al. [15] analysed 385 anal cancer patients treated with contemporary radiotherapy techniques, and demonstrated a $85.6 \%$ three-year overall survival. Initial complete clinical response rates were high at $86.7 \%$, but over time $24.4 \%$ of patients relapsed, with the majority of relapses $(83.4 \%)$ being local.

Establishing risk factors for oncological outcomes, in particular locoregional control following conformal chemoradiotherapy, could help optimise future treatment strategies and aid in the design and analysis of new clinical trials [16]. A consensus on prognostic factors could inform research by determining specific patient risk groups and the development of personalised treatment approaches, tailored to individual patient characteristics [17], and/or the introduction of novel agent combinations. This systematic review evaluates the literature to identify prognostic factors for a variety of disease-related outcomes in anal cancer, focusing on patients treated with curative intent using conformal radiotherapy techniques and contemporary treatment schedules.

\section{Methods}


A systematic review was undertaken according to PRISMA 2020 [18]. A comprehensive literature search was conducted using the Medline and Embase databases, to identify studies reporting on prognostic factors for survival and cancer-related outcomes after conformal chemoradiotherapy for anal cancer. The search terms included 'radiotherapy' AND 'anal cancer' AND 'prognostic factor', as well as related terms (see Appendix A for the full search strategies). Only studies published after $1^{\text {st }}$ January 2000 and up to and including $30^{\text {th }}$ June 2020 were considered. An initial scoping search showed that no studies conducted prior to 2000 had a majority of patients treated using conformal techniques.

Studies were included if they: (1) comprised of at least 70\% of patients treated with solely conformal radiotherapy techniques (3D-defined targets on CT, beams conformed to targets e.g. using multileaf collimators, 3D dose calculation and dose distribution optimisation), (2) reported survival or disease-related outcomes and (3) examined prognostic factors for outcomes using univariable (UVA) or multivariable (MVA) analysis. Studies were excluded if (1) patients were treated with 2D radiotherapy techniques and/or fields based solely on bony landmarks, if (2) cohorts included less than 100 patients or (3) were derived from population-level databases, or if (4) treatment with palliative intent. The cut-off of 100 patients was chosen to ensure that the prognostic factors identified are generalisable and to decrease the likelihood of identifying spurious prognostic factors from studies that suffer from small sample size bias. All (5) meta-analysis studies, reviews, animal model studies, conference abstracts/letters and studies without English translation were also excluded.

Two independent reviewers (ST and RS) screened and reviewed all relevant articles. A third independent reviewer (AA) assisted in reconciling differences in cases of disagreement. One reviewer (ST) extracted and analysed data from all relevant articles, including: study location, publication year, study design, source of participants, participant selection criteria, number of patients included, treatment period, radiotherapy technique administered, radiotherapy schedule, chemotherapy regimen, follow-up procedure, core clinical/patient characteristics, outcomes reported/definitions, statistical analysis used, prognostic variables tested, prognostic variables identified as significant and corresponding effect estimates. An independent reviewer (RS) repeated the data extraction from a subset (20\%) of all relevant articles to ensure that the data extraction process was reproducible. The methodological quality of all relevant articles was assessed independently by two reviewers (ST, RS) using the National Institutes of Health (NIH) Quality Assessment Tool for Case Series Studies [19]. Any disagreements were reviewed independently by a third reviewer (AA) to achieve consensus.

Reported outcomes and outcome definitions were extracted from each study and stratified into nine categories for further analysis. Disease activity and survival outcomes were firstly grouped according to the CORMAC review [20], which was used as the initial reporting framework for outcome stratification. Additional categories were inductively derived after the data extraction process.

For each study, factors analysed for their prognostic impact were extracted, whether they were shown to have a significant relationship with outcome, and the statistical method used for analysis. The factors were grouped into three broader categories: clinical factors, biomarkers and imaging factors. The total number of times a factor was tested in UVA for each of the nine outcomes was counted across all studies. Where factors tested were not reported explicitly, it was assumed that all reported patient characteristics were tested. Prognostic factors which were identified as significant in each study, along with their respective factor effect in the form of hazard ratios (HRs) were extracted (where available), and the proportion of times each factor was identified as prognostic for each outcome was calculated. Since the majority of studies did not report which factors were tested in MVA for each distinct outcome, the total number of times each factor was tested could not be counted. Therefore, only the prognostic factors and their respective factor effects were extracted. Only factors reported as prognostic in more than one study were included in the final results.

\section{Results}

\section{Literature search}

1567 studies published between $1^{\text {st }}$ January 2000 and $30^{\text {th }}$ June 2020 were identified, 404 of which were duplicates. Titles and abstracts of 1163 unique studies were screened. 1021 were excluded and the final 142 studies assessed for eligibility, of which 123 were excluded after reviewing the full text. 48 studies employed non-conformal radiotherapy techniques in more than $30 \%$ of patients. Other main factors for exclusion were sample size less than $100(n=29)$ and incomplete reporting on the radiotherapy technique ( $n=21)$. Ultimately, 19 studies [15, 21-38] were included in this literature review (Figure 1).

\section{Study characteristics}

Included studies were retrospective case series $(n=19)$, either single institutional $(n=10)$ or multi-institutional $(n=9)$. Patients were treated between 1989-2018 with median follow-up range of 14.9-70.0 months. The most common radiotherapy techniques employed were a combination of 3D-CRT and IMRT/VMAT $(n=9)$, followed by IMRT only $(n=6)$. Dose ranged from $45 \mathrm{~Gy} / 25$ fractions to $63 \mathrm{~Gy} / 35$ fractions and chemotherapy regimens were mainly MMC and 5-FU based, with three studies including the option of cisplatin. Statistical techniques for UVA were log-rank tests (n=12) and univariable Cox regression ( $n=9)$, with four studies using both. Multivariable Cox regression was applied for MVA in all but one study, which used logistic regression instead. Regarding quality, 16 were deemed good and three deemed fair (Appendix B). A short follow-up (of less than 36 months, 
as used for the primary endpoint in the PLATO trial [17]) was a common issue in eight studies. Due to the lack of universal reporting of effect sizes for prognostic factors, it was not possible to carry out a meta-analysis on the data. Table 1 presents the main characteristics for all included studies (Appendix C presents a more detailed version including information on cancer subtype and location in the included cohorts, TNM staging version used and all predictors tested).

\section{Outcomes}

Outcome definitions varied considerably. Appendix D presents the definitions extracted from each study and how they were categorised. Nine outcome categories were used: three disease activity (freedom-from-disease, locoregional failure (LRF) and distant failure) as well as six survival categories (overall survival (OS), disease-free survival (DFS), colostomy-free survival (CFS), cancer-specific survival, local failure-free survival and metastasis-free survival (MFS)). Disease-free survival and progression-free survival were grouped together, as definitions overlapped in most papers. Local and regional failures were grouped with locoregional failures, due to the small number of studies reporting only on the latter. Freedom-from-disease, a category which was not included in CORMAC, was devised in order to include definitions of time-to-recurrence, time-tofailure (not specified as local, regional or distant) and disease-free survival where death was not considered an event. Commonly investigated outcomes were OS $(n=17)$, LRF $(n=11)$ and DFS $(n=11)$. Appendix E lists all outcomes reported, along with all factors tested.

\section{Clinical prognostic factors}

Table 2 presents clinical factors identified as prognostic for each outcome in more than one study, categorised by UVA and MVA. For prognostic factors identified in MVA, the range of factor effects (HRs) across studies is also reported. Eight unique prognostic factors were established by more than one study in UVA and seven in MVA (See Appendix $F$ for full results).

In UVA, T stage, $\mathrm{N}$ stage and sex were the most commonly tested factors for all seven outcomes for which prognostic factors were identified (Table 1). $T$ stage was prognostic for all outcomes; in $56 \%$ of the studies that tested it for OS, in $64 \%$ for LRF, in $40 \%$ for DFS, in $100 \%$ for MFS, in $67 \%$ for freedom-from-disease, in $75 \%$ for CFS and in $67 \%$ for cancer-specific survival. Similarly, N stage was prognostic for six of seven outcomes. It was prognostic in $63 \%$ of the studies testing for OS, in $64 \%$ for LRF, in $44 \%$ for DFS, in $100 \%$ for MFS, in $100 \%$ for freedom-from-disease and in $67 \%$ for cancer-specific survival. The third most identified prognostic factor in UVA was sex. It was prognostic for five of the seven outcomes, in $58 \%$ of the studies that tested it for OS, in $56 \%$ for LRF, in $63 \%$ for DFS, in $50 \%$ for MFS and in $67 \%$ for freedom-from-disease. Performance status was also identified as prognostic in $75 \%$ of the studies that tested it for OS, and in $100 \%$ of studies that tested it for LRF.

In MVA, sex retained its prognostic significance, appearing as the predominant prognostic factor for six of the seven outcomes, altogether identified in nine studies [15, 21, 22, 25, 27-29, 35, 37]. Other commonly identified prognostic factors included higher T stage (OS, DFS, MFS and CFS; identified in seven studies [21-23, 26, 28, 34, 37]) and higher N stage (OS, LRF, DFS, MFS; identified in seven studies [15, 21, 23, 25, 26, 30, 36]). The rest of the factors were identified as prognostic for a single outcome only; age and AJCC stage for OS, as well as incomplete/interrupted radiotherapy and performance status for LRF.

\section{Biomarkers and imaging prognostic factors}

A smaller number of studies $(n=8)$ examined the prognostic significance of biomarkers $[25,27-30,35,36,38]$. Only four unique biomarkers were deemed prognostic overall by more than one study in both UVA and MVA (Table 3 and Appendix G).

In UVA, HPV16 load from pre-treatment biopsies was found to be prognostic for OS (2/3 - $67 \%$ of studies [27, 28]) and for LRF (2/3 - 67\% of studies [27, 28]), whereas the presence of baseline neutrophilia (circulating blood neutrophil count of more than $7500 / \mathrm{mm} 3$ in one study and more than $7 \mathrm{G} / \mathrm{L}$ in the second study) was found to be prognostic for OS $(2 / 2-100 \%$ of studies $[29,36])$ and DFS $(2 / 2-100 \%$ of studies $[29,36])$. Additionally, baseline anaemia (haemoglobin count $<13 \mathrm{~g} / \mathrm{dL}$ ) was deemed prognostic for OS only $(2 / 2-100 \%$ of studies [29, 36]) and the presence of baseline leukocytosis markers (white blood cell count $>10000 / \mathrm{mm} 3$ in one study and more than 10G/L in the second study) for DFS only.

In MVA, baseline neutrophilia retained its prognostic significance for both OS (two studies [29, 36]) and DFS (two studies [29, 36]), whereas HPV16 load retained its prognostic significance for LRF (two studies $[27,28]$ ) only. Baseline leukocytosis was found to be prognostic for DFS (two studies $[29,36])$ and for OS (two studies [29, 36]). Lastly, baseline anaemia was identified as prognostic for DFS (two studies [29, 36]) only.

Only two studies [23,33] investigated imaging-related prognostic factors. In UVA, one study [33] identified post-treatment PET-CT SUVmax (positron emission tomography and computed tomography maximum standardized uptake value) and change in SUVmax (pre- vs. post-treatment) to be prognostic for OS. The pre-treatment and post-treatment SUVmax values were both found to be prognostic for local failure-free survival. In MVA, the post-treatment SUVmax and the change in SUVmax retained prognostic significance for OS. In the second study [23], a selection of radiomics 
markers were identified as prognostic for DFS (Appendix H). For local failure-free survival, only the high post-treatment SUVmax was deemed prognostic in MVA (Appendix $\mathrm{H})$.

\section{Discussion}

This systematic review summarises the findings from studies examining prognostic factors for anal cancer outcomes following CRT with contemporary conformal radiotherapy techniques. By limiting our findings to studies with cohorts treated with conformal radiotherapy techniques, we aimed to ensure that the prognostic factors identified are the most informative to current practice and are representative of the more prevalent HPV-driven biology and the higher survival rates which have been observed in the past few years. $\mathrm{N}$ stage, $\mathrm{T}$ stage, and sex were established as the most prevalent and reliable clinical prognostic factors for the majority of outcomes explored, in both UVA and MVA. Few biomarkers have been identified as prognostic by more than one study: pre-treatment biopsy HPV load, as well as the presence of leukocytosis, neutrophilia and anaemia at baseline measurement. The review also highlighted the lack of studies with large cohorts exploring the prognostic significance of imaging factors.

Due to the rarity of anal cancer, only few randomised prospective clinical trials have been conducted to date; none of which have employed conformal radiotherapy techniques and reported on prognostic factors. Reports from randomised trials using non-conformal radiotherapy techniques support the prognostic role of $\mathrm{N}$ stage, T stage and sex [3,39]. Male sex and a higher $\mathrm{N}$ stage were found to be strong prognostic indicators for worse OS [3,40,41], for higher risk of local failure [3,42] and LRF [41]. The prognostic role of T stage was less apparent, since higher $T$ stage was only found to be prognostic for worse OS [40] and local failure [42]. Our results suggest that a higher $T$ stage is prognostic for higher risk of LRF in UVA, but not in MVA. Although the aforementioned trials used highly standardised approaches and studied a relatively large number of patients, crude radiotherapy techniques were employed, therefore the prescribed and received radiotherapy doses are likely to differ significantly [43].

In terms of tumour biomarkers, HPV status is the strongest previously-established prognostic indicator in anal cancer [44, 45]. A previous study [46] also established the prognostic significance of p16 INK4A in anal cancer, a biomarker commonly used as a surrogate for HPV involvement. In line with these findings, our results confirm the prognostic role of pre-treatment biopsy HPV load in anal cancer. Treatment modification based on HPV status is currently being tested in a head and neck cancer clinical trial, where treatment is stratified based on the HPV status of the cancer [47]. Apart from HPV load, no other tumour biomarkers were identified as prognostic in this review. In terms of haematological biomarkers, long-term outcome data from the ACT1 randomised controlled trial reported that a higher baseline white blood cell count is prognostic for worse OS [41], supporting our results (Table 3). Baseline anaemia, another haematological biomarker identified as prognostic in our review, may carry important clinical implications. Although not predictive of OS in the ACT1 data, it was independently predictive of anal cancer death. In cervical cancer, another HPV-driven cancer, blood transfusions are given if haemoglobin levels are below $10 \mathrm{~g} / \mathrm{dl}$ prior to CRT and this may be an area of future clinical consideration in anal cancer treatment.

Due to the lack of studies exploring imaging factors, it is difficult to put our review findings into perspective. Future radiomics research in this setting should focus on multicentre cohorts; but we also noted the lack of secondary or explorative radiomics research from prospective trials. Further research in this area may for instance help identify tumour volumes of greater radiotherapy resistance for boosting.

Three other reviews have previously investigated prognostic factors for anal cancer. One systematic review focused solely on biomarkers and did not include any information on general, pathological or treatment-related prognostic factors [48]. A second systematic review examined the prognostic factors for the specific subset of HIV-positive anal cancer patients undergoing highly active antiretroviral therapy (HAART) [49]. The third review [50] explored clinical, treatment-related as well as molecular prognostic factors, but was a narrative rather than a systematic review. None focused specifically on identifying prognostic factors for outcomes after conformal radiotherapy.

The current work has several limitations. As anal cancer is rare, reports exploring this topic are often single-centre studies with small cohorts, meaning that the power to identify relevant prognostic factors, especially factors with relatively limited effect size or with low prevalence, may be limited. Any factors identified and their effect estimates may suffer from small sample bias [51]. We opted for a sample size of 100 patients as the cut-off point, following an initial screen of available studies, in order to ensure that a reasonable number of studies could be included in the final analysis and the factors identified were generalisable. Through the initial screen, only 43 studies which had cohorts of more than 20 patients were identified. If studies with 20-100 patients had been included, seven additional studies exploring biomarkers and 12 additional studies exploring imaging factors would have been considered, and a larger number of factors would potentially be identified as prognostic. Only few of the studies included in this review distinguished between cancers of the anal canal and perianal cancers (Appendix $\mathrm{C}$ ). Therefore, it was not possible to identify prognostic factors for a specific tumour location or subtype. Additionally, the TNM staging version used varied from the $6^{\text {th }}$ edition to the $8^{\text {th }}$ edition across studies (Appendix $\mathrm{C}$ ) and some studies did not report the version used at all. As a result, in this review all tumour and nodal staging information was analysed together, without accounting for the version used.

There was large variation in treatment regimens, factors tested and outcome definitions between studies. This renders the identification of prognostic factors for anal cancer challenging and highlights the need for uniform outcome definitions, not only in clinical trials and research, but

Page 5/16 
also in routine clinical practice [52]. The studies themselves suffer from several limitations as well, especially in the statistical methodology. The majority of studies applied a univariable screening technique to select factors for MVA. Generally, univariable screening should be avoided for such analyses, as it invalidates the effect and significance estimates in MVA [53, 54], and more robust approaches should be used instead [53, 55]. Moreover, a considerable number of studies did not report on factor effects acquired from UVA or MVA, therefore we could not summarise factor effects across studies. Since a meta-analysis could not be conducted, only a summary of factor effects is reported in this review. Lastly, the proportion of times each factor was identified as prognostic, which is a better indicator of the reliability of the prognostic significance of a factor, could not be calculated from MVA results, due to a lack of detail about the total number of times each factor was tested for each outcome.

Overall, this study confirms the prognostic value of only few well-established clinical factors and biomarkers relevant to contemporary clinical practice. No novel prognostic factors have been identified. This emphasises the lack of studies with large cohorts treated with conformal radiotherapy that report on prognostic factors, especially studies exploring biomarkers and imaging factors. In spite of the remarkable advances in anal cancer treatment efficacy and the reduction of toxicity through conformal CRT, our understanding of the biomarker and imaging factors that predict the outcomes of this disease is still very limited. To tackle the challenge of prognostic factor identification, larger multi-institutional studies and prospective clinical trials would need to be conducted, not only on a national scale, but also on an international scale using approaches that link data across borders [56].

\section{Conclusion}

This systematic review confirms the following prognostic factors for outcomes following anal cancer treatment with conformal CRT: T stage, $\mathrm{N}$ stage, sex, pre-treatment biopsy HPV load, as well as the presence of baseline leukocytosis, neutrophilia and anaemia. The prognostic information presented can be used as a starting point for variable selection in future prognostic modelling studies. Additionally, by establishing a set of prognostic and potentially predictive factors for anal cancer outcomes, we may be able to stratify patients into risk groups in order to design more personalised clinical trials in the future. Radiotherapy dose modification based on risk by $\mathrm{T}$ and $\mathrm{N}$ stage is being evaluated in the currently recruiting PLATO clinical trial [17], with translational research into prognostic biomarkers and imaging embedded within the trial design. This will in turn provide us with greater insight into how to effectively treat this disease using a more personalised approach.

\section{Abbreviations}

\begin{tabular}{|c|c|}
\hline Abbreviation & Meaning \\
\hline $5-\mathrm{FU}$ & 5-fluorouracil \\
\hline ASCC & Anal squamous cell carcinoma \\
\hline CRT & Chemoradiotherapy \\
\hline CFS & Colostomy-free survival \\
\hline CT & Computed tomography \\
\hline DFS & Disease-free survival \\
\hline HR & Hazard ratio \\
\hline HPV & Human papillomavirus \\
\hline IMRT & Intensity modulated radiotherapy \\
\hline LRF & Locoregional failure \\
\hline SUVmax & Maximum standardized uptake value \\
\hline MFS & Metastasis-free survival \\
\hline MMC & Mitomycin C \\
\hline MVA & Multivariable analysis \\
\hline $\mathrm{NIH}$ & National Institutes of Health \\
\hline OAR & Organs at risk \\
\hline OS & Overall survival \\
\hline PET & Positron emission tomography \\
\hline UVA & Univariable analysis \\
\hline VMAT & Volumetric arc therapy \\
\hline
\end{tabular}

Page 6/16 


\section{Declarations}

\section{Ethics approval and consent to participate}

Not applicable

\section{Consent for publication}

Not applicable

\section{Availability of data and materials}

All data generated or analysed during this study are included in this published article [and its supplementary information files].

\section{Competing interests}

The authors declare that they have no competing interests.

\section{Funding}

The authors would like to acknowledge Cancer Research UK funding (grant C19942/A28832) for the Leeds Radiotherapy Research Centre of Excellence (RadNet). Ane Appelt is supported by Yorkshire Cancer Research Academic Fellowship funding (grant L389AA). None of the funders have had any involvement in the study design; in the collection, analysis and interpretation of data; in the writing of the report; or in the decision to submit the article for publication.

\section{Authors' contributions}

ST, AA and AG conceived the study idea and formulated the research question. ST carried out the literature search. ST and RS screened the articles which were identified through the literature search, selected the relevant articles to be reviewed, extracted the data, analysed the data and evaluated the methodological quality of the articles. ST prepared the initial draft manuscript. AA, AG, RS, DSM, AH and JL critically reviewed and edited the draft manuscript. ST revised the manuscript and prepared the final version. All authors read and approved the final manuscript.

\section{Acknowledgements}

Not applicable

\section{References}

1. Nigro ND, Vaitkevicius VK, Considine B. Combined therapy for cancer of the anal canal: A preliminary report. Dis Colon Rectum. 1974;17:354-6.

2. Flam M, John M, Pajak TF, Petrelli N, Myerson R, Doggett S, et al. Role of mitomycin in combination with fluorouracil and radiotherapy, and of salvage chemoradiation in the definitive nonsurgical treatment of epidermoid carcinoma of the anal canal: results of a phase III randomized intergroup study. J Clin Oncol. 1996;14:2527-39.

3. Bartelink H, Roelofsen F, Eschwege F, Rougier P, Bosset JF, Gonzalez DG, et al. Concomitant radiotherapy and chemotherapy is superior to radiotherapy alone in the treatment of locally advanced anal cancer: results of a phase III randomized trial of the European Organization for Research and Treatment of Cancer Radiotherapy and Gastrointestinal Cooperative Groups. J Clin Oncol. 1997;15:2040-9.

4. Murray LJ, Lilley J. Radiotherapy: technical aspects. Medicine (Baltimore). 2020;48:79-83.

5. Muirhead R, Adams RA, Gilbert DC, Harrison M, Glynne-Jones R, Sebag-Montefiore D, et al. National guidance for IMRT in anal cancer. 2016. http://analimrtguidance.co.uk/national-anal-imrt-guidance-v3.pdf. Accessed 31 Jan 2022.

6. UKCCCR Anal Cancer Trial Working Party. Epidermoid anal cancer: results from the UKCCCR randomised trial of radiotherapy alone versus radiotherapy, 5-fluorouracil, and mitomycin. The Lancet. 1996;348:1049-54. 
7. Gunderson LL, Winter KA, Ajani JA, Pedersen JE, Moughan J, Benson AB 3rd, et al. Long-term update of US GI intergroup RTOG 98-11 phase III trial for anal carcinoma: survival, relapse, and colostomy failure with concurrent chemoradiation involving fluorouracil/mitomycin versus fluorouracil/cisplatin. J Clin Oncol. 2012;30:4344-51.

8. Peiffert D, Tournier-Rangeard L, Gérard J-P, Lemanski C, François E, Giovannini M, et al. Induction Chemotherapy and Dose Intensification of the Radiation Boost in Locally Advanced Anal Canal Carcinoma: Final Analysis of the Randomized UNICANCER ACCORD 03 Trial. J Clin Oncol. 2012;30:1941-8.

9. James RD, Glynne-Jones R, Meadows HM, Cunningham D, Myint AS, Saunders MP, et al. Mitomycin or cisplatin chemoradiation with or without maintenance chemotherapy for treatment of squamous-cell carcinoma of the anus (ACT II): a randomised, phase 3 , open-label, $2 \times 2$ factorial trial. Lancet Oncol. 2013;14:516-24.

10. Kachnic LA, Winter K, Myerson RJ, Goodyear MD, Willins J, Esthappan J, et al. RTOG 0529: a phase 2 evaluation of dose-painted intensity modulated radiation therapy in combination with 5 -fluorouracil and mitomycin- $\mathrm{C}$ for the reduction of acute morbidity in carcinoma of the anal canal. Int J Radiat Oncol Biol Phys. 2013;86:27-33.

11. Jones MP, Hruby G, Metser U, Sridharan S, Capp A, Kumar M, et al. FDG-PET parameters predict for recurrence in anal cancer - results from a prospective, multicentre clinical trial. Radiat Oncol Lond Engl. 2019;14:140.

12. Wang J, Zhang H, Chuong M, Latifi K, Tan S, Choi W, et al. Prediction of Anal Cancer Recurrence After Chemoradiotherapy Using Quantitative Image Features Extracted From Serial 18F-FDG PET/CT. Front Oncol. 2019;9:934.

13. Das P, Bhatia S, Eng C, Ajani JA, Skibber JM, Rodriguez-Bigas MA, et al. Predictors and Patterns of Recurrence After Definitive Chemoradiation for Anal Cancer. Int J Radiat Oncol. 2007;68:794-800.

14. Tomaszewski JM, Link E, Leong T, Heriot A, Vazquez M, Chander S, et al. Twenty-five-year experience with radical chemoradiation for anal cancer. Int J Radiat Oncol. 2012;83:552-8.

15. Shakir R, Adams R, Cooper R, Downing A, Geh I, Gilbert D, et al. Patterns and Predictors of Relapse Following Radical Chemoradiation Therapy Delivered Using Intensity Modulated Radiation Therapy With a Simultaneous Integrated Boost in Anal Squamous Cell Carcinoma. Int $\mathrm{J}$ Radiat Oncol. 2020;106:329-39.

16. Halabi S, Owzar K. The Importance of Identifying and Validating Prognostic Factors in Oncology. Semin Oncol. 2010;37:e9-18.

17. ISRCTN registry [Internet]. London: BMC. ISRCTN88455282, PLATO - Personalising anal cancer radiotherapy dose. 2016.

18. Page MJ, McKenzie JE, Bossuyt PM, Boutron I, Hoffmann TC, Mulrow CD, et al. The PRISMA 2020 statement: an updated guideline for reporting systematic reviews. BMJ. 2021;:n71.

19. National Institutes of Health. Study quality assessment tools. 2014. https://www. nhlbi. nih. gov/health-topics/study-quality-assessment-tools. Accessed 11 Jun 2021.

20. Fish R, Sanders C, Ryan N, der Veer SV, Renehan AG, Williamson PR. Systematic review of outcome measures following chemoradiotherapy for the treatment of anal cancer (CORMAC). Colorectal Dis Off J Assoc Coloproctology G B Irel. 2018;20:371-82.

21. Martin D, Rödel F, von der Grün J, Rödel C, Fokas E. Acute organ toxicity correlates with better clinical outcome after chemoradiotherapy in patients with anal carcinoma. Radiother Oncol. 2020;149:168-73.

22. de Meric de Bellefon M, Lemanski C, Castan F, Samalin E, Mazard T, Lenglet A, et al. Long-term follow-up experience in anal canal cancer treated with Intensity-Modulated Radiation Therapy: Clinical outcomes, patterns of relapse and predictors of failure. Radiother Oncol. 2020;144:141-7.

23. Brown PJ, Zhong J, Frood R, Currie S, Gilbert A, Appelt AL, et al. Prediction of outcome in anal squamous cell carcinoma using radiomic feature analysis of pre-treatment FDG PET-CT. Eur J Nucl Med Mol Imaging. 2019;46:2790-9.

24. Rouard N, Peiffert D, Rio E, Mahé M-A, Delpon G, Marchesi V, et al. Intensity-modulated radiation therapy of anal squamous cell carcinoma: Relationship between delineation quality and regional recurrence. Radiother Oncol J Eur Soc Ther Radiol Oncol. 2019;131:93-100.

25. Franco P, Montagnani F, Arcadipane F, Casadei C, Andrikou K, Martini S, et al. The prognostic role of hemoglobin levels in patients undergoing concurrent chemo-radiation for anal cancer. Radiat Oncol Lond Engl. 2018;13:83.

26. Call JA, Prendergast BM, Jensen LG, Ord CB, Goodman KA, Jacob R, et al. Intensity-modulated Radiation Therapy for Anal Cancer: Results From a Multi-Institutional Retrospective Cohort Study. Am J Clin Oncol. 2016;39:8-12. 
27. Balermpas P, Martin D, Wieland U, Rave-Fränk M, Strebhardt K, Rödel C, et al. Human papilloma virus load and PD-1/PD-L1, CD8+ and FOXP3 in anal cancer patients treated with chemoradiotherapy: Rationale for immunotherapy. Oncolmmunology. $2017 ; 6: \mathrm{e} 1288331$.

28. Rödel F, Steinhäuser K, Kreis N-N, Friemel A, Martin D, Wieland U, et al. Prognostic impact of RITA expression in patients with anal squamous cell carcinoma treated with chemoradiotherapy. Radiother Oncol J Eur Soc Ther Radiol Oncol. 2018;126:214-21.

29. Schernberg A, Huguet F, Moureau-Zabotto L, Chargari C, Rivin Del Campo E, Schlienger M, et al. External validation of leukocytosis and neutrophilia as a prognostic marker in anal carcinoma treated with definitive chemoradiation. Radiother Oncol J Eur Soc Ther Radiol Oncol. 2017;124:110-7.

30. Martin D, Rödel F, Balermpas P, Winkelmann R, Fokas E, Rödel C. C-Reactive Protein-to-Albumin Ratio as Prognostic Marker for Anal Squamous Cell Carcinoma Treated With Chemoradiotherapy. Front Oncol. 2019;9:1200.

31. Oehler-Jänne C, Huguet F, Provencher S, Seifert B, Negretti L, Riener M-O, et al. HIV-specific differences in outcome of squamous cell carcinoma of the anal canal: a multicentric cohort study of HIV-positive patients receiving highly active antiretroviral therapy. J Clin Oncol. 2008;26:2550-7.

32. Susko M, Wang C-CJ, Lazar AA, Kim S, Laffan A, Feng M, et al. Factors Impacting Differential Outcomes in the Definitive Radiation Treatment of Anal Cancer Between HIV-Positive and HIV-Negative Patients. The oncologist. 2020. https://doi.org/10.1634/theoncologist.2019-0824.

33. Cardenas ML, Spencer CR, Markovina S, DeWees TA, Mazur TR, Weiner AA, et al. Quantitative FDG-PET/CT predicts local recurrence and survival for squamous cell carcinoma of the anus. Adv Radiat Oncol. 2017;2:281-7.

34. Bitterman DS, Grew D, Gu P, Cohen RF, Sanfilippo NJ, Leichman CG, et al. Comparison of anal cancer outcomes in public and private hospital patients treated at a single radiation oncology center. J Gastrointest Oncol. 2015;6:524-33.

35. Fraunholz I, Rödel F, Kohler D, Diallo-Georgiopoulou M, Distel L, Falk S, et al. Epidermal growth factor receptor expression as prognostic marker in patients with anal carcinoma treated with concurrent chemoradiation therapy. Int J Radiat Oncol Biol Phys. 2013;86:901-7.

36. Schernberg A, Escande A, Rivin Del Campo E, Ducreux M, Nguyen F, Goere D, et al. Leukocytosis and neutrophilia predicts outcome in anal cancer. Radiother Oncol J Eur Soc Ther Radiol Oncol. 2017;122:137-45.

37. Hosni A, Han K, Le LW, Ringash J, Brierley J, Wong R, et al. The ongoing challenge of large anal cancers: prospective long term outcomes of intensity-modulated radiation therapy with concurrent chemotherapy. Oncotarget. 2018;9:20439-50.

38. Oblak I, Cesnjevar M, Anzic M, Hadzic JB, Ermenc AS, Anderluh F, et al. The impact of anaemia on treatment outcome in patients with squamous cell carcinoma of anal canal and anal margin. Radiol Oncol. 2016;50:113-20.

39. Ajani JA, Winter KA, Gunderson LL, Pedersen J, Benson AB, Thomas CR, et al. Prognostic factors derived from a prospective database dictate clinical biology of anal cancer: The intergroup trial (RTOG 98-11). Cancer. 2010;116:4007-13.

40. Bilimoria KY, Bentrem DJ, Rock CE, Stewart AK, Ko CY, Halverson A. Outcomes and Prognostic Factors for Squamous-Cell Carcinoma of the Anal Canal: Analysis of Patients From the National Cancer Data Base. Dis Colon Rectum. 2009;52:624-31.

41. Glynne-Jones R, Sebag-Montefiore D, Adams R, Gollins S, Harrison M, Meadows HM, et al. Prognostic factors for recurrence and survival in anal cancer: generating hypotheses from the mature outcomes of the first United Kingdom Coordinating Committee on Cancer Research Anal Cancer Trial (ACT I). Cancer. 2013;119:748-55.

42. Johnsson A, Leon O, Gunnlaugsson A, Nilsson P, Höglund P. Determinants for local tumour control probability after radiotherapy of anal cancer. Radiother Oncol. 2018;128:380-6.

43. Aggarwal A, Gayadeen S, Robinson D, Hoskin PJ, Mawdsley S, Harrison M, et al. Clinical target volumes in anal cancer: Calculating what dose was likely to have been delivered in the UK ACT II trial protocol. Radiother Oncol. 2012;103:341-6.

44. Gilbert DC, Wakeham K, Langley RE, Vale CL. Increased risk of second cancers at sites associated with HPV after a prior HPV-associated malignancy, a systematic review and meta-analysis. Br J Cancer. 2019;120:256-68.

45. Serup-Hansen E, Linnemann D, Skovrider-Ruminski W, Høgdall E, Geertsen PF, Havsteen H. Human Papillomavirus Genotyping and p16 Expression As Prognostic Factors for Patients With American Joint Committee on Cancer Stages I to III Carcinoma of the Anal Canal. J Clin Oncol. 2014;32:1812-7.

46. Gilbert DC, Serup-Hansen E, Linnemann D, Høgdall E, Bailey C, Summers J, et al. Tumour-infiltrating lymphocyte scores effectively stratify outcomes over and above p16 post chemo-radiotherapy in anal cancer. Br J Cancer. 2016;114:134-7. 
47. Owadally W, Hurt C, Timmins H, Parsons E, Townsend S, Patterson J, et al. PATHOS: a phase II/III trial of risk-stratified, reduced intensity adjuvant treatment in patients undergoing transoral surgery for Human papillomavirus (HPV) positive oropharyngeal cancer. BMC Cancer. 2015;15:602.

48. Lampejo T, Kavanagh D, Clark J, Goldin R, Osborn M, Ziprin P, et al. Prognostic biomarkers in squamous cell carcinoma of the anus: a systematic review. Br J Cancer. 2010;103:1858-69.

49. Correa RJM, Louie AV, Virine B, Dinniwell R, Kaiser A, Mishra MV. A Systematic Review of Clinical Outcomes Following Chemoadiation Therapy for Anal Cancer in HIV-Positive Patients on Highly Active Antiretroviral Therapy. Int J Radiat Oncol. 2017;99:E142.

50. Das P, Crane CH, Eng C, Ajani JA. Prognostic factors for squamous cell cancer of the anal canal. Gastrointest Cancer Res GCR. 2008;2:10-4.

51. Hackshaw A. Small studies: strengths and limitations. Eur Respir J. 2008;32:1141-3.

52. Fish R, Sanders C, Adams R, Brewer J, Brookes ST, DeNardo J, et al. A core outcome set for clinical trials of chemoradiotherapy interventions for anal cancer (CORMAC): a patient and health-care professional consensus. Lancet Gastroenterol Hepatol. 2018;3:865-73.

53. Heinze G, Wallisch C, Dunkler D. Variable selection - A review and recommendations for the practicing statistician. Biom J. 2018;60:431-49.

54. Sun G-W, Shook TL, Kay GL. Inappropriate use of bivariable analysis to screen risk factors for use in multivariable analysis. J Clin Epidemiol. 1996;49:907-16.

55. Sanchez-Pinto LN, Venable LR, Fahrenbach J, Churpek MM. Comparison of variable selection methods for clinical predictive modeling. Int J Med Inf. 2018;116:10-7.

56. Theophanous S, Choudhury A, Lønne P-I, Samuel R, Guren MG, Berbee M, et al. Predicting outcomes in anal cancer patients using multi-centre data and distributed learning - A proof-of-concept study. Radiother Oncol. 2021;159:183-9.

\section{Tables}

Table 1. Overview of study characteristics, including treatment techniques and regimens. 


\begin{tabular}{|c|c|c|c|c|c|c|c|c|c|c|}
\hline \# & Study & Location & $\begin{array}{l}\text { Number } \\
\text { of } \\
\text { patients }\end{array}$ & $\begin{array}{l}\text { Years of } \\
\text { treatment }\end{array}$ & $\begin{array}{l}\text { Radiotherapy } \\
\text { technique }\end{array}$ & $\begin{array}{l}\text { Radiotherapy } \\
\text { regimen }\end{array}$ & $\begin{array}{l}\text { Chemotherapy } \\
\text { regimen }\end{array}$ & $\begin{array}{l}\text { Median } \\
\text { follow- } \\
\text { up } \\
\text { (months) }\end{array}$ & $\begin{array}{l}\text { Type of } \\
\text { statistical } \\
\text { analysis } \\
\text { used }\end{array}$ & Quality \\
\hline 1 & $\begin{array}{l}\text { Shakir et } \\
\text { al. (2020) } \\
{[15]}\end{array}$ & MC, EU & 385 & $\begin{array}{l}2013- \\
2018\end{array}$ & IMRT & $\begin{array}{l}50.4 \mathrm{~Gy} / 28 \\
\text { fractions for } \\
\mathrm{T} 1 / 2 \mathrm{~N} 0 \text {, } \\
53.2 \mathrm{~Gy} / 28 \\
\text { fractions for } \\
\mathrm{T} 1 / 2 \mathrm{~N}+\text { or } \\
\mathrm{T} 3 / 4 \mathrm{Nany}\end{array}$ & $\begin{array}{l}\text { MMC and Cap } \\
\text { or } 5 \text {-FU }\end{array}$ & 24.0 & $\begin{array}{l}\text { UV Cox, } \\
\text { MV Cox }\end{array}$ & Good \\
\hline 2 & $\begin{array}{l}\text { Martin et } \\
\text { al. (2020) } \\
\text { [21] }\end{array}$ & SC, EU & 223 & $\begin{array}{l}1996- \\
2017\end{array}$ & $\begin{array}{l}\text { 3D-CRT } \\
(58 \%) \\
\text { IMRT }(42 \%)\end{array}$ & $\begin{array}{l}50-50.4 \mathrm{~Gy} \text { in } \\
1.8- \\
2 \mathrm{~Gy} / \text { fraction, } \\
\text { boost of } 5.4-9 \\
\text { Gy }\end{array}$ & $\begin{array}{l}\text { 5-FU and } \\
\text { MMC or Cisp }\end{array}$ & 46.0 & $\begin{array}{l}\text { UV Cox, } \\
\text { MV Cox }\end{array}$ & Good \\
\hline 3 & $\begin{array}{l}\text { de Bellefon } \\
\text { et al. } \\
(2020) \\
{[22]}\end{array}$ & SC, EU & 193 & $\begin{array}{l}2005- \\
2017\end{array}$ & IMRT & $\begin{array}{l}45 G y \text { in } \\
1.8 \mathrm{~Gy} / \text { fraction, } \\
\text { boost of } 14.4- \\
20 \mathrm{~Gy}(1.8-2 \\
\text { Gy/fraction) }\end{array}$ & $\begin{array}{l}5-\mathrm{FU} \text { and } \\
\text { MMC }\end{array}$ & 70.0 & $\begin{array}{l}\text { UV Cox, } \\
\text { MV Cox }\end{array}$ & Good \\
\hline 4 & $\begin{array}{l}\text { Brown et } \\
\text { al. (2019) } \\
{[23]}\end{array}$ & SC, EU & 189 & $\begin{array}{l}2008- \\
2016\end{array}$ & $\begin{array}{l}\text { 2D/3D-CRT } \\
(79 \%) \\
\text { VMAT }(21 \%)\end{array}$ & $\begin{array}{l}49.6 \mathrm{~Gy} \text { in } \\
1.8 \mathrm{~Gy} / \text { fraction }\end{array}$ & $\begin{array}{l}5-\mathrm{FU} \text { and } \\
\mathrm{MMC}\end{array}$ & 35.1 & $\begin{array}{l}\text { MV } \\
\text { logistic }\end{array}$ & Good \\
\hline 5 & $\begin{array}{l}\text { Rouard et } \\
\text { al. (2019) } \\
{[24]}\end{array}$ & MC, EU & 165 & $\begin{array}{l}2006- \\
2016\end{array}$ & IMRT & $\begin{array}{l}45-50 \mathrm{~Gy} \text { in } \\
1.8 \text { or } \\
2 \mathrm{~Gy} / \text { fraction, } \\
\text { boost of } 15- \\
20 \mathrm{~Gy}\end{array}$ & $\begin{array}{l}5-F U \text { and } \\
\text { MMC }\end{array}$ & 33.8 & $\begin{array}{l}\text { BV Cox, } \\
\text { MV Cox }\end{array}$ & Good \\
\hline 6 & $\begin{array}{l}\text { Franco et } \\
\text { al. (2018) } \\
{[25]}\end{array}$ & $\mathrm{MC}, \mathrm{EU}$ & 161 & NR & IMRT & $\begin{array}{l}50-50.4 G y \text { in } \\
1.8- \\
2 \text { Gy/fraction }\end{array}$ & $\begin{array}{l}\text { 5-FU and } \\
\text { MMC }\end{array}$ & 27.0 & $\begin{array}{l}\text { Log-rank, } \\
\text { UV Cox, } \\
\text { MV Cox }\end{array}$ & Good \\
\hline 7 & $\begin{array}{l}\text { Call et al. } \\
(2016) \\
{[26]}\end{array}$ & $\mathrm{MC}, \mathrm{NA}$ & 152 & NR & IMRT & $\begin{array}{l}51.25 \mathrm{~Gy} / 28 \\
\text { fractions }\end{array}$ & $\begin{array}{l}5-\mathrm{FU} \text { and } \\
\text { MMC (75\% of } \\
\text { patients) }\end{array}$ & 26.8 & $\begin{array}{l}\text { Log-rank, } \\
\text { MV Cox }\end{array}$ & Fair \\
\hline 8 & $\begin{array}{l}\text { Balermpas } \\
\text { et al. } \\
(2017) \\
{[27]}\end{array}$ & MC, EU & 150 & NR & $\begin{array}{l}\text { 3D-CRT } \\
\text { IMRT }\end{array}$ & $\begin{array}{l}53.4 \mathrm{~Gy} \text { in } 1.8- \\
2 \mathrm{~Gy} / \text { fraction }\end{array}$ & $\begin{array}{l}\text { 5-FU and } \\
\text { MMC }\end{array}$ & 40.0 & $\begin{array}{l}\text { Log-rank, } \\
\text { MV Cox }\end{array}$ & Good \\
\hline 9 & $\begin{array}{l}\text { Rodel et al. } \\
\text { (2018) } \\
{[28]}\end{array}$ & MC, EU & 140 & NR & $\begin{array}{l}\text { 3D-CRT } \\
\text { IMRT }\end{array}$ & $\begin{array}{l}\text { 53.4Gy (range } \\
46.8-64.8 \mathrm{~Gy} \text { ) }\end{array}$ & $\begin{array}{l}\text { 5-FU and } \\
\text { MMC }\end{array}$ & 40.0 & $\begin{array}{l}\text { Log-rank, } \\
\text { MV Cox }\end{array}$ & Good \\
\hline 10 & $\begin{array}{l}\text { Schernberg } \\
\text { et al. } \\
(2017) \\
{[29]}\end{array}$ & MC, EU & 133 & $\begin{array}{l}2000- \\
2015\end{array}$ & $\begin{array}{l}\text { IMRT (77\%) } \\
\text { 3D-CRT } \\
(23 \%)\end{array}$ & $\begin{array}{l}49.5 \mathrm{~Gy} / 30 \\
\text { fractions } \\
\text { (centre } 1) \\
45 \mathrm{~Gy} / 25 \\
\text { fractions } \\
\text { (centre 2) }\end{array}$ & $\begin{array}{l}\text { Cisp and 5-FU } \\
\text { or Cap / MMC } \\
\text { and 5-FU or } \\
\text { Cap }\end{array}$ & 37.4 & $\begin{array}{l}\text { Log-rank, } \\
\text { MV Cox }\end{array}$ & Good \\
\hline 11 & $\begin{array}{l}\text { Martin et } \\
\text { al. (2019) } \\
{[30]}\end{array}$ & SC, EU & 126 & $\begin{array}{l}2004- \\
2016\end{array}$ & $\begin{array}{l}\text { IMRT (65\%) } \\
\text { 3D-CRT } \\
(35 \%)\end{array}$ & $\begin{array}{l}59.4 \mathrm{~Gy} \text { in } 1.8 \\
\text { or } \\
2 \mathrm{~Gy} / \text { fraction }\end{array}$ & $\begin{array}{l}\text { 5-FU and } \\
\text { MMC }\end{array}$ & NR & $\begin{array}{l}\text { Log-rank, } \\
\text { UV Cox, } \\
\text { MV Cox }\end{array}$ & Good \\
\hline 12 & $\begin{array}{l}\text { Oehler- } \\
\text { Janne et } \\
\text { al. }(2008) \\
{[31]}\end{array}$ & MC, IN & 121 & $\begin{array}{l}1997- \\
2006\end{array}$ & 3D-CRT & $\begin{array}{l}\text { 52Gy-60Gy } \\
\text { depending on } \\
\text { centre }\end{array}$ & $\begin{array}{l}\text { 5-FU and } \\
\text { MMC or Cisp }\end{array}$ & 36.0 & $\begin{array}{l}\text { Log-rank, } \\
\text { UV Cox, } \\
\text { MV Cox }\end{array}$ & Good \\
\hline 13 & $\begin{array}{l}\text { Susko et } \\
\text { al. (2020) } \\
{[32]}\end{array}$ & SC, NA & 111 & $\begin{array}{l}2005- \\
2018\end{array}$ & $\begin{array}{l}\text { 3D-CRT } \\
\text { IMRT }\end{array}$ & $\begin{array}{l}55.8 \mathrm{~Gy} / 30 \\
\text { fractions }\end{array}$ & $\begin{array}{l}\text { 5-FU and } \\
\text { MMC }\end{array}$ & 28.0 & $\begin{array}{l}\text { Log-rank, } \\
\text { UV Cox, } \\
\text { MV Cox }\end{array}$ & Good \\
\hline 14 & $\begin{array}{l}\text { Cardenas } \\
\text { et al. } \\
(2017)\end{array}$ & SC, NA & 110 & $\begin{array}{l}2003- \\
2013\end{array}$ & IMRT (75\%) & $\begin{array}{l}50.4 \mathrm{~Gy} / 28 \\
\text { fractions for } \\
\text { T2N0, }\end{array}$ & $\begin{array}{l}5-F U \text { and } \\
\text { MMC }\end{array}$ & 28.6 & $\begin{array}{l}\text { UV Cox, } \\
\text { MV Cox }\end{array}$ & Fair \\
\hline
\end{tabular}


[33]

2D-CRT $\quad 54 \mathrm{~Gy} / 30$

(25\%) fractions for

T3/4Nany

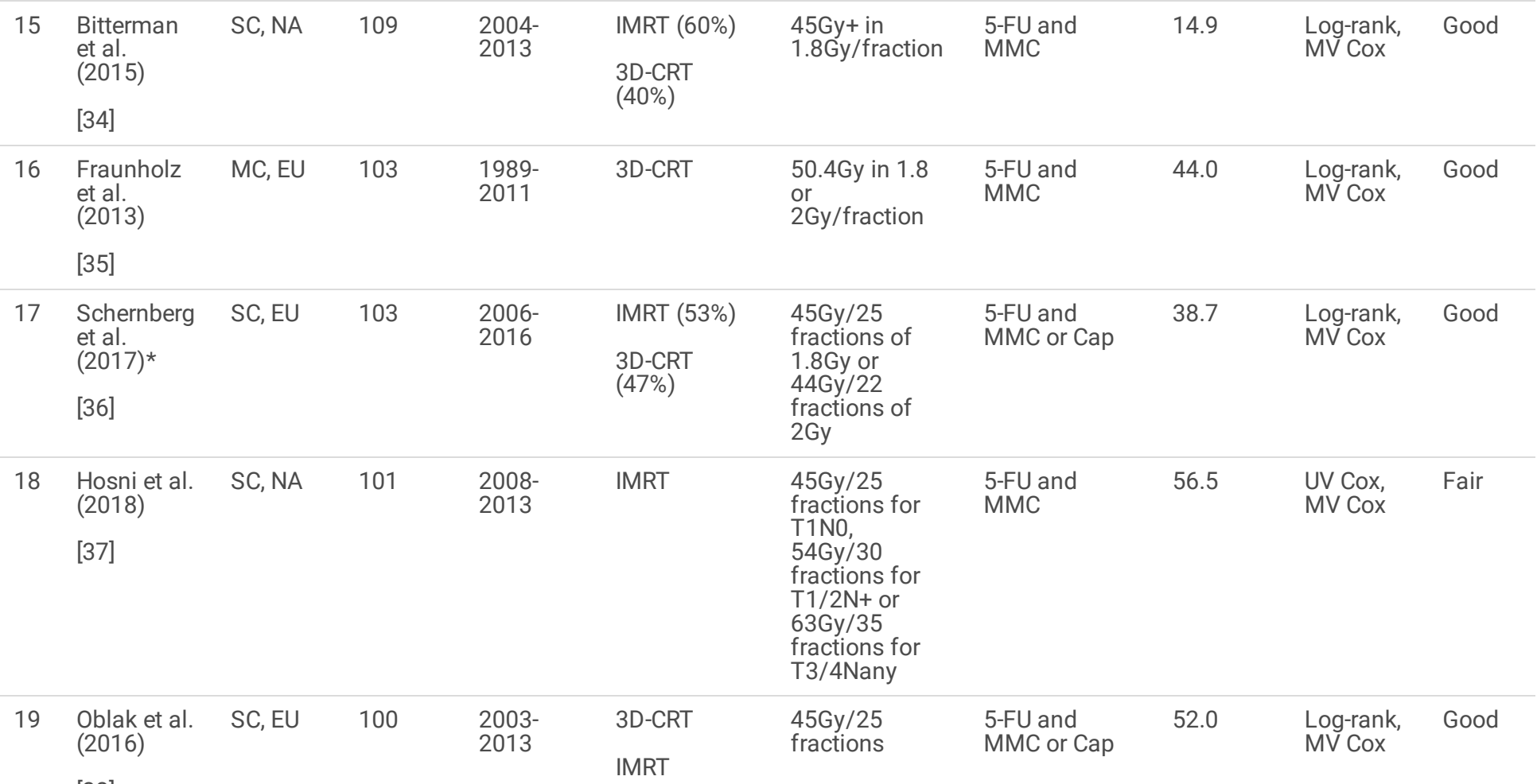

[38]

* used to differentiate between two studies by the same author published in the same year. MC: multi-centre. SC: single-centre. EU: Europe.

NA: North America. IN: International. NR: not reported. Gy: Gray. MMC: mitomycin C. Cap: capecitabine. 5-FU: 5-fluorouracil. Cisp: cisplatin.

UV: univariable. BV: bivariable. MV: multivariable. Cox: Cox regression. Log-rank: log-rank statistical test.

Table 2. Clinical factors identified as prognostic for worse outcomes by more than one study. 


\begin{tabular}{|c|c|c|c|c|}
\hline \multicolumn{5}{|l|}{ Univariable analysis } \\
\hline $\begin{array}{l}\text { Outcome } \\
\text { (number of studies reporting } \\
\text { outcome) }\end{array}$ & Factor & $\begin{array}{l}\text { Times identified as } \\
\text { prognostic }\end{array}$ & $\begin{array}{l}\text { Total times } \\
\text { tested }\end{array}$ & $\begin{array}{l}\text { Studies which identified factor as } \\
\text { prognostic }\end{array}$ \\
\hline \multirow{7}{*}{$\begin{array}{l}\text { Overall survival } \\
(n=17)\end{array}$} & Higher N stage & 10 & 16 & $\begin{array}{l}{[15],[21],[22],[25],[26],[27],[28],[35],} \\
{[36],[38]}\end{array}$ \\
\hline & Higher T stage & 9 & 16 & $\begin{array}{l}{[15],[21],[22],[27],[28],[35],[36],[37],} \\
{[38]}\end{array}$ \\
\hline & Male sex & 7 & 12 & [15],[21],[25],,27],[28],,29],[37] \\
\hline & Worse performance status & 3 & 4 & {$[15],[29],[38]$} \\
\hline & Older age & 3 & 4 & {$[24],[27],[37]$} \\
\hline & $\begin{array}{l}\text { Incomplete/interrupted RT } \\
\text { or breaks }\end{array}$ & 2 & 2 & [15],[24] \\
\hline & Longer CRT duration & 2 & 5 & {$[36],[38]$} \\
\hline \multirow{5}{*}{$\begin{array}{l}\text { Locoregional failure } \\
(n=11)\end{array}$} & Higher N stage & 7 & 11 & [15],[21],[26],[27],[28],[30],[38] \\
\hline & Higher T stage & 7 & 11 & [15],[21],[26],[27],[28],[32],[38] \\
\hline & Male sex & 5 & 9 & {$[15],[21],[27],[28],[29]$} \\
\hline & Worse performance status & 4 & 4 & {$[15],[24],[29],[38]$} \\
\hline & Longer CRT duration & 2 & 2 & [32],[38] \\
\hline \multirow[t]{3}{*}{ Disease-free survival $(n=11)$} & Male sex & 5 & 8 & [21],[27],[29],,30],[37] \\
\hline & Higher $\mathrm{N}$ stage & 4 & 9 & {$[21],[22],[27],[30]$} \\
\hline & Higher T stage & 4 & 10 & {$[21],[22],[28],[37]$} \\
\hline \multirow{3}{*}{$\begin{array}{l}\text { Metastasis-free survival } \\
(n=5)\end{array}$} & Higher T stage & 5 & 5 & {$[21],[22],[30],[35],[36]$} \\
\hline & Higher $\mathrm{N}$ stage & 4 & 4 & {$[21],[30],[35],[36]$} \\
\hline & Male sex & 2 & 4 & [21],[30] \\
\hline \multirow{3}{*}{$\begin{array}{l}\text { Freedom from disease } \\
(n=4)\end{array}$} & Higher N stage & 4 & 4 & {$[15],[28],[31],[38]$} \\
\hline & Male sex & 2 & 3 & [15],[28] \\
\hline & Higher T stage & 2 & 3 & [15],[38] \\
\hline \multicolumn{5}{|l|}{$\begin{array}{l}\text { Colostomy-free survival } \\
(n=4)\end{array}$} \\
\hline \multirow{2}{*}{$\begin{array}{l}\text { Cancer-specific survival } \\
(n=3)\end{array}$} & Higher T stage & 2 & 3 & [35],[38] \\
\hline & Higher $\mathrm{N}$ stage & 2 & 3 & [35],[38] \\
\hline \multicolumn{5}{|l|}{ Multivariable analysis } \\
\hline $\begin{array}{l}\text { Outcome } \\
\text { (number of studies reporting } \\
\text { outcome) }\end{array}$ & Factor & $\begin{array}{l}\text { Times identified as } \\
\text { prognostic }\end{array}$ & $\begin{array}{l}\text { Factor effect } \\
\text { range (HR) }\end{array}$ & $\begin{array}{l}\text { Studies which identified factor as } \\
\text { prognostic }\end{array}$ \\
\hline \multirow{5}{*}{$\begin{array}{l}\text { Overall survival } \\
(n=17)\end{array}$} & Male sex & 7 & $1.92-4.80$ & [15],[21],[25],,27],[28],,[29],[37] \\
\hline & Higher T stage & 3 & $2-88-4.98$ & {$[22],[34],[37]$} \\
\hline & Older age & 3 & $1.05-2.43$ & {$[24],[37],[37]$} \\
\hline & Higher N stage & 3 & $1.88-5.80$ & {$[25],[26],[36]$} \\
\hline & Higher AJCC stage & 2 & $2.23-2.82$ & {$[22],[38]$} \\
\hline Locoregional failure & Male sex & 4 & $2.08-3.40$ & {$[15],[21],[27],[29]$} \\
\hline
\end{tabular}




\begin{tabular}{|c|c|c|c|c|}
\hline \multirow{4}{*}{$(n=11)^{-}$} & \\
\hline & Higher $\mathrm{N}$ stage & 3 & $2.23-3.58$ & {$[15],[21],[30]$} \\
\hline & $\begin{array}{l}\text { Incomplete/interrupted RT } \\
\text { or breaks }\end{array}$ & 2 & $2.47-4.96$ & {$[15],[22]$} \\
\hline & Worse performance status & 2 & $3.82-5.50$ & {$[24],[29]$} \\
\hline \multirow{3}{*}{$\begin{array}{l}\text { Disease-free survival } \\
(n=11)\end{array}$} & Male sex & 4 & $2.13-3.60$ & {$[21],[27],[29],[37]$} \\
\hline & Higher T stage & 3 & $2.57-7.02$ & {$[22],[23],[37]$} \\
\hline & Higher $\mathrm{N}$ stage & 2 & $\mathrm{~N} / \mathrm{A}^{*}$ & {$[21],[23]$} \\
\hline \multirow{3}{*}{$\begin{array}{l}\text { Metastasis-free survival } \\
(n=5)\end{array}$} & Male sex & 2 & $3.87-4.08$ & {$[21],[23]$} \\
\hline & Higher T stage & 2 & $2.61-3.54$ & {$[21],[22]$} \\
\hline & Higher N stage & 2 & $2.41-4.49$ & {$[21],[30]$} \\
\hline \multirow[b]{2}{*}{$\begin{array}{l}\text { Freedom from disease } \\
(n=4)\end{array}$} & Male sex & 2 & $2.16-2.16$ & {$[15],[28]$} \\
\hline & & & & \\
\hline $\begin{array}{l}\text { Colostomy-free survival } \\
(n=4)\end{array}$ & Higher T stage & 3 & $3.65-4.10$ & {$[22],[26],[37]$} \\
\hline
\end{tabular}

These clinical factors were identified through univariable and multivariable analysis, and were stratified by outcome. A number of studies reported on "gender", however this was analysed in conjunction with "sex" throughout the study, since "sex" is used when reporting on biological factors instead of gender identity, or psychosocial or cultural factors. HR: Hazard Ratio. N/A: Not available. *Factor effects (HRs) were provided by only one study for this prognostic factor, therefore the effect range could not be determined.

Table 3. Biomarkers identified as prognostic for worse outcomes by more than one study. 


\begin{tabular}{|c|c|c|c|c|}
\hline \multicolumn{5}{|l|}{ Univariable analysis } \\
\hline $\begin{array}{l}\text { Outcome } \\
\text { (number of studies reporting } \\
\text { outcome) }\end{array}$ & Factor & $\begin{array}{l}\text { Times identified as } \\
\text { prognostic }\end{array}$ & Total times tested & $\begin{array}{l}\text { Studies which identified factor as } \\
\text { prognostic }\end{array}$ \\
\hline \multirow{3}{*}{$\begin{array}{l}\text { Overall survival } \\
(n=17)\end{array}$} & $\begin{array}{l}\text { Lower HPV16 } \\
\text { load }\end{array}$ & 2 & 3 & {$[27],[28]$} \\
\hline & Neutrophilia & 2 & 2 & {$[29],[36]$} \\
\hline & Anaemia & 2 & 2 & {$[29],[36]$} \\
\hline \multicolumn{5}{|l|}{$\begin{array}{l}\text { Locoregional failure } \\
(n=11)\end{array}$} \\
\hline \multirow{2}{*}{$\begin{array}{l}\text { Disease-free survival } \\
(n=11)\end{array}$} & Leukocytosis & 2 & 2 & {$[29],[36]$} \\
\hline & Neutrophilia & 2 & 2 & {$[29],[36]$} \\
\hline \multicolumn{5}{|l|}{ Multivariable analysis } \\
\hline $\begin{array}{l}\text { Outcome } \\
\text { (number of studies reporting } \\
\text { outcome) }\end{array}$ & Factor & $\begin{array}{l}\text { Times identified as } \\
\text { prognostic }\end{array}$ & $\begin{array}{l}\text { Factor effect range } \\
\text { (HR) }\end{array}$ & $\begin{array}{l}\text { Studies which identified factor as } \\
\text { prognostic }\end{array}$ \\
\hline \multirow{2}{*}{$\begin{array}{l}\text { Overall survival } \\
(n=17)\end{array}$} & Leukocytosis & 2 & $4.60-19.90$ & {$[29],[36]$} \\
\hline & Neutrophilia & 2 & $4.40-22.70$ & {$[29],[36]$} \\
\hline $\begin{array}{l}\text { Locoregional failure } \\
(n=11)\end{array}$ & $\begin{array}{l}\text { Lower HPV16 } \\
\text { load }\end{array}$ & 2 & $3.57-4.51$ & {$[27],[28]$} \\
\hline \multirow{3}{*}{$\begin{array}{l}\text { Disease-free survival } \\
(n=11)\end{array}$} & Leukocytosis & 2 & $6.90-7.10$ & {$[29],[36]$} \\
\hline & Neutrophilia & 2 & $5.00-7.60$ & {$[29],[36]$} \\
\hline & Anaemia & 2 & $2.50-5.30$ & {$[29],[36]$} \\
\hline
\end{tabular}

These biomarkers were identified through univariable and multivariable analysis and were stratified by outcome. HPV: human papillomavirus. HR: Hazard ratio.

\section{Figures}




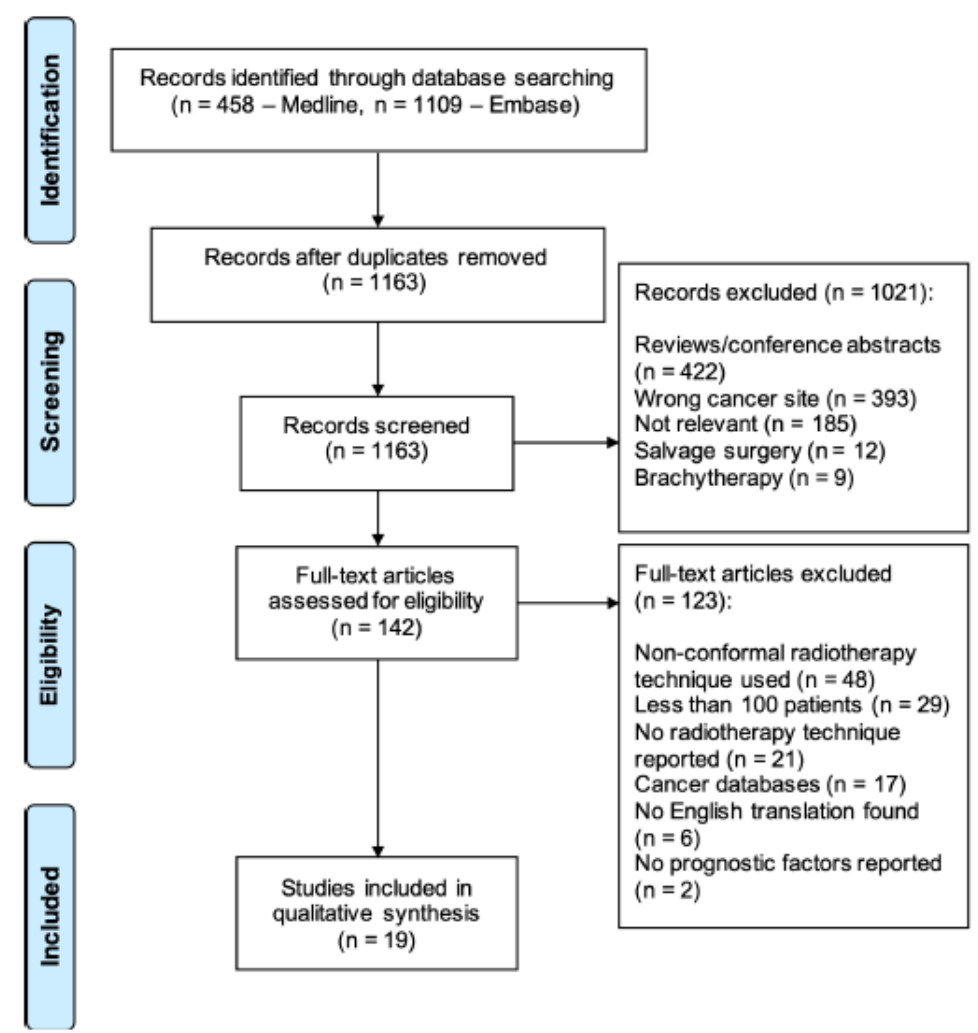

Figure 1

PRISMA flow diagram depicting the number of studies that were identified, included and excluded, and the reasons for exclusion.

\section{Supplementary Files}

This is a list of supplementary files associated with this preprint. Click to download.

- AppendicesAH.pdf 